\title{
Social media, a strategic tool for the recruitment process.
}

\author{
Deshati E* \\ Business Administration Department, Canadian Institute of Technology, Albania
}

Accepted on December 06, 2017

The social media phenomenon has opened up new paths of engagement and revolutionized the way people exchange information. As social media technology continues to evolve and becomes more widespread, it presents an exciting opportunity for the recruitment industry.

This writing reflects on issues concerning social media recruitment in private sector and it aims to raise the awareness of businesses and HR professionals on how the use of social media can positively impact the recruitment process, and how social media could serve as a potential tool for recruitment.

In the context of the contemporary global business environment, the role of social media has increased drastically and recruiters find that they need to be more proactive in their approach, by engaging with talent across a wide range of social networking platforms. The take-up of social media has naturally led companies to consider its use as a recruitment tool. Considering that social media has entered the business landscape and particularly the recruitment landscape, leads to a demand for knowledge about recruitment trends regarding social media.

There are several authors that have researched the use of social media in recruitment process. Blacksmith et al. [1] state that "Social media sites are no longer just a place to keep in touch with friend and family. They have entered the workspace and are influencing the way recruitment and hiring is implemented. Hauptman et al. [2] emphasize that: "In terms of professional work, social media can be said to be relatively easy and inexpensive to introduce. Social media can be especially helpful to human resource management when it comes to facilitating personnel recruitment, promoting learning processes on an individual, team and organizational level". Redman et al. [3] believe that the main reason for the transition to social media as a recruitment tool is "cost and speed". Hunt [4] states that "companies that do not embrace social media as a recruitment tool might risk losing qualitative candidates to their competition that is focused on such outreach".

The recruitment process is considered key to the success of a company. Recruitment is the process of attracting and encouraging potential employees to apply for a position, while selection is the process of making fair and relevant assessment of the strengths and weaknesses of applicants with the intention to hire them [5], therefore companies would be more than interested on identifying methods to help them hire the most skilled and talented employees in the market. Since the use of social media is largely increasing, it is crucial for the businesses to use such tool for the recruitment process. Social media could be a powerful tool for a company that could be used to advertise jobs, and create a competitive advantage since it can reach a greater pool of potential candidates.

Since the beginning of the social media era, communication has become extremely convenient and effective. The traditional ways of putting out a job vacancy and waiting for people to come to you are a thing of the past in most industries. Nowadays companies focus more on social media, rather than using newspapers, media, word of mouth, or recruitment agencies. However in the past years the use of social media has transformed the recruitment process for many companies worldwide. "Social media can be a powerful tool a company can use to its advantage" [6]. But what are social Medias? Social media platforms can be defined as information technologies which support interpersonal communication and collaboration using internet-based platforms. Such social medias have actually changed the way how people nowadays communicate and interact with each-other. Social Medias such as Facebook, Twitter and Linked-In are used by hundreds of millions of people every day all over the world. According to a 2015 Society for Human Resources (SHRM) study that surveyed recruiters, LinkedIn, Facebook and Twitter are the most popular social networks for recruiters. Google+, YouTube, Instagram and Pinterest are runner-ups, but are still strong niche recruiting options.

According to Hootsuite, a social media management platform, in January 2017 there have been registered [7]:

\section{Worldwide}

3.773 billion internet users (10\% growth from January 2016)

2.789 billion users are active social media users $(21 \%$ growth from January 2016)

One of the fastest-growing recruiting trends in recent years has been social recruiting, using social media networks such as Facebook, LinkedIn and Twitter to source and recruit candidates. Recruitment through social media can offer many benefits to companies, as it allows them to reach a larger pool of potential candidates.

Compared to traditional tools, social media recruitments can generate a higher interest on the job posting as the announcement is seen by a great number of individuals. Another benefit of using social media is the low/no cost for placing the announcement for the vacant position, always 
compared to the high costs of announcements through media. The speed of response would also be a benefit of recruitment through social media, since the time for making the announcement visible to the public is really short, compared to traditional announcement placed in the newspapers, TV, radio or employment agencies. While levels of awareness and adoption continue to develop both for recruiters and job applicants, organizations must consider adding social media to their overall recruitment strategy to meet the goals of being cost effective, right on target, and strategic; remaining competitive; and sourcing top talent. Social media is a great tool for recruitment and it should be further explored by the business sector and HR professionals.

\section{References}

1. Blacksmith N, Poeppelman T. Application of modern technology and social media in the workplace. The Industrial-Organizational Psychologist. 2014;51:69-73.
2. Hauptmann S, Steger T. A brave new (digital) world. Effects of in-house social media on HRM. Jour Zeitschrift Fur Personalforschung. 2013;27:26-46.

3. Redman T, Wilkinson A. Contemporary human resource management text and cases. Third Edition. London: Pearson Education. 2009.

4. Hunt K. Finders keepers: Social media strategies help find top talent. Journal of Property Management. 2010;75:3640 .

5. Sutherland $\mathrm{M}$, Wöcke $\mathrm{A}$ The symptoms and consequences to selection errors in recruitment decisions. S Afr J Bus Manag. 2011;42:23-32.

6. Russell R, Stutz M. Social media: What employers need to know. J Internet Law. 2014;17:3-6.

7. Digital in 2017: Southern Europe. Hootsuite 2017.

\section{*Correspondence to:}

Deshati E

Business Administration Department

Canadian Institute of Technology

Albania

E-mail: erjona-deshati@hotmail.com 